\title{
An Opportunistic Activity-sensing Approach to Save Energy in Office Buildings
}

\author{
Marija Milenkovic \\ ACTLab, Signal Processing Systems \\ Electrical Engineering, TU Eindhoven \\ P.O. Box 513, NL-5600 MB Eindhoven \\ m.milenkovic@tue.nl
}

\author{
Oliver Amft \\ ACTLab, Signal Processing Systems \\ Electrical Engineering, TU Eindhoven \\ P.O. Box 513, NL-5600 MB Eindhoven \\ o.amft@tue.nl
}

\begin{abstract}
In this work, we recognised office worker activities that are relevant for energy-related control of appliances and building systems using sensors that are commonly installed in new or refurbished office buildings. We considered desk-related activities and people count in office rooms, structured into desk- and room-cells. Recognition was performed using finite state machines (FSMs) and probabilistic layered hidden Markov models (LHMMs).

We evaluated our approach in a real living-lab office, including three private and multi-person office rooms. As example devices, we used different ceiling-mounted PIR sensors based on the EnOcean platform and plug-in power meters. In at least five days of study data per office room, including reference sensor data and occupant annotations, we confirmed that activities can be recognised using these sensors. For computer and desk work, an overall recognition accuracy of $95 \%$ was achieved. People count was estimated at $87 \%$ and $78 \%$ for the best-performing two office rooms. We furthermore present building simulation results that compare different control strategies. Compared to modern BEMS, our results show that $21.9 \%$ and $19.5 \%$ of electrical energy can be saved for controls based on recognised desk activity and estimated people count, respectively. These results confirm the relevance of building energy management based on activity sensing.
\end{abstract}

\section{Categories and Subject Descriptors}

G.3 [Probability and Statistics]: Probabilistic algorithms (including Monte Carlo), Statistical computing; I.2.6 [Arti-ficial Intelligence]: Learning-Parameter learning; I.5.1 [Pattern Recognition]: Models-Deterministic, Statistical; I.5.2 [Pattern Recognition]: Design MethodologyClassifier design and evaluation, Feature evaluation and selection, Pattern analysis; I.6.6 [Simulation and

Modeling]: Applications

Permission to make digital or hard copies of all or part of this work for personal or classroom use is granted without fee provided that copies are not made or distributed for profit or commercial advantage and that copies bear this notice and the full citation on the first page. To copy otherwise, to republish, to post on servers or to redistribute to lists, requires prior specific permission and/or a fee.

e-Energy'13, May 21-24, 2013, Berkeley, California, USA

Copyright 2013 ACM 978-1-4503-2052-8/13/05 ...\$15.00.

\section{Keywords}

Activity recognition; office buildings; green ICT; energy saving, BEMS

\section{INTRODUCTION}

Commercial buildings are among the largest energy consumers and $\mathrm{CO}_{2}$ producers worldwide [7]. While efficiency improvements in installation and appliances can contribute to lower consumption and cost, a large additional potential for energy savings exists in actively controlling building spaces according to their actual dynamic usage. Modern Building (Energy) Management Systems (BMS, BEMS) typically operate by adjusting heating, ventilation and airconditioning (HVAC) and lighting based on readings from various types of sensors distributed within a building. Besides room conditions (e.g., temperature, humidity, light level), motion sensors and energy meters are frequently installed sensing modalities in new or refurbished commercial buildings. Although most energy consumers in offices support rapid control cycles and different operating states, the data provided by building sensors is not fully exploited in current BEMS. Where BEMS systems do not adapt dynamically to occupant activities energy could be wasted. In particular, dynamic information on user activities is currently not considered for building control. For example, to properly ventilate a building space, the actual people count in the office space is key to adjust air supply and temperature in order to maintain user comfort, as suggested by the ANSI/ASHRAE standard [2]. According to Erickson and Cerpa [5] an occupancy-driven ventilation strategy alone could reduce total energy usage by $8.1 \%$. Through a business day, office building users follow various activities and occupy different building spaces. Current buildings only use presence or motion detectors in offices to switch lights on or off according to occupancy. Standby power detectors are used to switch off devices that remain in low-power mode, while not being used.

More detailed information on office activities could save energy. For example, detecting whether users perform paperbased or computer-based work could enable BEMS to dim lights during screen-work and increase lighting levels during paper-based work as well as to control office appliances [12]. To date, most approaches to activity recognition in offices relied on a variety of specifically added sensors, such as video and ultrasound sensors, or required users to use wearable technology (see related work in Sec. 2). In those approaches, the set of commonly installed and networked sensors that are available for BEMS management was not considered. 
Adding and maintaining further sensors increases cost and burden for building management, thus should be minimised. Using existing sensors could provide options for activitybased control, ideally by updating BEMS software only.

In this paper we investigate an opportunistic approach to office activity recognition by using a subset of sensors that can be frequently found readily installed in office buildings. Our aim is thus to derive a set of activities that is relevant for energy-related control of appliances and building systems (HVAC, lighting, other office appliances). We then evaluate activity recognition performance using the opportunistic, hence often available, sensor set. In particular, this paper provides the following contributions:

1. We present our activity recognition and energy saving approach using sensors frequently installed in buildings. We detail our recognition approach using finite and probabilistic state models that can be applied with building sensor data. We recognise activities that have potential to lead to energy savings, including desk work activities and people count per office.

2. We give an overview on the living-lab installation of three different office rooms, in which we investigated our opportunistic sensing approach in a continuous recording study during five or more days per room. While occupants followed their regular office activities, data from the various in-building sensors were acquired together with complementary reference sensors to subsequently analyze recognition performances.

3. We determine the relevance of the considered activity sets regarding their energy saving potential using simulations. Here we compare several commonly used control strategies in buildings with our activity-based approach. Along the installation of our living-lab building, we illustrate the potential energy saving using opportunistic activity-based sensing.

Relations of office activities and building energy requirements have been shown previously through simulations. However, the feasibility of using standard office building sensors to recognise activities, which are relevant for energy saving, yet has to been confirmed. In this paper, we focus on identifying relevant office activities and recognition approaches as a first, but essential step towards improving energy efficient building operations. For this purpose, our work considers real offices, where participants work regularly.

\section{RELATED WORK}

Passive infrared sensors (PIR) are widely used in activity recognition, but most commonly in presence and motion detection, to track people's paths, in order to switch on and off lights, HVAC systems, and appliances. In [1] PIR sensors and magnetic door switches were used to detect occupancy of certain building spaces and control the HVAC system accordingly. Using information about occupancy from a pilot testbed and building simulation, potential energy savings between $10 \%$ to $15 \%$ were estimated.

Besides HVAC system control, PIR sensors together with other sensor modalities are commonly used for controlling lighting and appliances. In a work of Marchiori and Qi [13], PIR sensors and door switches were used together with energy controllers to manage different office appliances accord- ing to occupancy. Authors in [4] used motion and light sensors to determine high energy consumption points that can be optimized to gain greater efficiency. Their energy consumption optimization was based on occupancy and the level of ambient and artificial light. Savings from $58.6 \%$ in openplan offices to $70.9 \%$ in corridors were estimated. To learn occupancy patterns and movement behavior, authors in [6] and [5] used wireless cameras. Camera nodes were placed at the boundaries between different areas to detect transition between them. Besides tracking people, the approach was used to estimate the number of people in the room and to predict room usage. Based on known occupancy patterns, HVAC control strategies could be optimized to save $8.1 \%$ of energy needs.

In several previous works, occupancy information was considered for control purposes. Even though occupancy information has proven to be valuable for controlling lighting, HVAC, and different appliances, and previous studies showed substantial energy saving potential, those works did not consider actual user activity. Our present study focuses on occupant activity and behaviour as a key information for building adaptation and energy saving, thus not limited to occupancy only.

Wojek et al. [23] used cameras and omni-directional microphones for room-level people tracking in offices and laboratories. The authors recognized whether users were participating in meetings, involved in discussions, paper work, phone calls, or the office was empty. Oliver and Horwitz used USB cameras and binaural microphones for detecting office activities $[17,18]$. Based on audio data they were able to differentiate human speech, music, silence, ambient noise, phone ringing and typing. From video data, the system detected whether people were present in the office. At the highest layer in their model, activities, such as phone conversation, ongoing presentation, distant conversation, nobody in the office, and user present and engaged in some other activity were modelled. Since cameras and microphones are often considered to reveal privacy-sensitive details, authors in [24] proposed solution for user activity recognition and tracking by using a network of PIR sensors only. They grouped sensors into clusters to represent e.g. entering, leaving, tuning, walking up and down. Superclusters were used to model visiting, chatting and meeting activities. Their approach required a dense installation of PIR sensors. In [16] authors used PIR, pressure sensors and microphones for recognizing five different activities: working with $\mathrm{PC}$, working without PC, having a meeting, presence, and absence. Jahn et al. [11] proposed ubiquitous sensor-based system for tracking user actions relevant for sustainable behaviour. In particular, power consumption, presence, lighting, window movement, and heating temperature was monitored. The work showed that user behaviour and awareness is relevant for reducing energy waste.

Studies investigating office activity recognition showed that high performance could be reached for several sensor modalities and information sources. Although cameras and microphones would provide rich information about user activities, they are often considered privacy-intrusive by occupants, and thus could affect user behaviour and comfort. PIR sensors and plug-in power meters, as used for motion detection and power measurements of computer screens in our study, could provide sufficient information to recognise activity. Since both, PIRs and plug-in power meters are 
regularly used in offices already, acceptance by occupants is likely. Furthermore, previous works on office activity recognition did not consider activities related to energy saving potential, as it is targeted in our study.

Opportunistic sensing approaches have been investigated to combat the constraints in obtrusiveness, privacy, and cost associated to the previously mentioned concepts, which are key to our application too. In the context of smart homes, infrastructure-mediated sensing or 'home bus snooping' was investigated to recognize user activities by single-point sensing. Patel et al. [20] analyzed electricity line noise of different device in homes. By observing the device operation, the authors derived information about user location and activity. In the approach of Froehlich et al. [9] water fixtures were monitored, including sink, toilet, shower, bathtub, clothes washer and dishwasher. Another approach was proposed by Patel et al. [19] for detecting human movement by differential pressure sensing at the home-based HVAC system. According to differential pressure it was possible to determine location of pressure disturbances and determine when people were passing through doorways as well as to detect door opening and closing. Although these approaches are easy to deploy and very promising, they are mainly applicable to private houses.

Our approach focuses on identifying activities in office buildings, where a single-point sensing approaches are not feasible due to the larger variability in installed appliances, variety in occupant behavior patterns, and need for scalable sensing solutions. We thus consider an opportunistic sensing approach that relies on modalities often available in modern or refurbished buildings.

In [10] and [22] authors used user access badges, identification via Wi-Fi points, user calendars, Instant Messaging clients, and computer system activity, in order to track users and recognize their activities. With this rich information about users, these opportunistic approaches showed good recognition accuracies and potential for energy saving. In contrast, our approach considers motion as a binary signal and energy consumption of computer screens only. In this work, sensor data is not used to identify users, neither to track them.

\section{RECOGNITION CONCEPT}

Our opportunistic sensing and recognition approach builds on a subset of sensors that are often already installed in office buildings. This section details modalities considered and describes the office activity recognition algorithms developed to derive activity information from the sensors.

\subsection{Opportunistic in-building activity sensing}

Since energy conservation and cost represent major challenges for building operators and facility managers, various wired and wireless in-building sensing systems have been introduced to support BMS control. Among them, motion detectors are typically used to control lights in different zones. Lights are switched on and off according to user presence. Power meters are used to measure consumption of plug-in appliances. Figure 1 illustrates the modalities commonly available and considered for activity recognition in this work.

Depending on building type and primary occupant use, additional modalities could be available, such as window switches (where windows can be opened), temperature, humidity, and many further modalities. In our approach, we

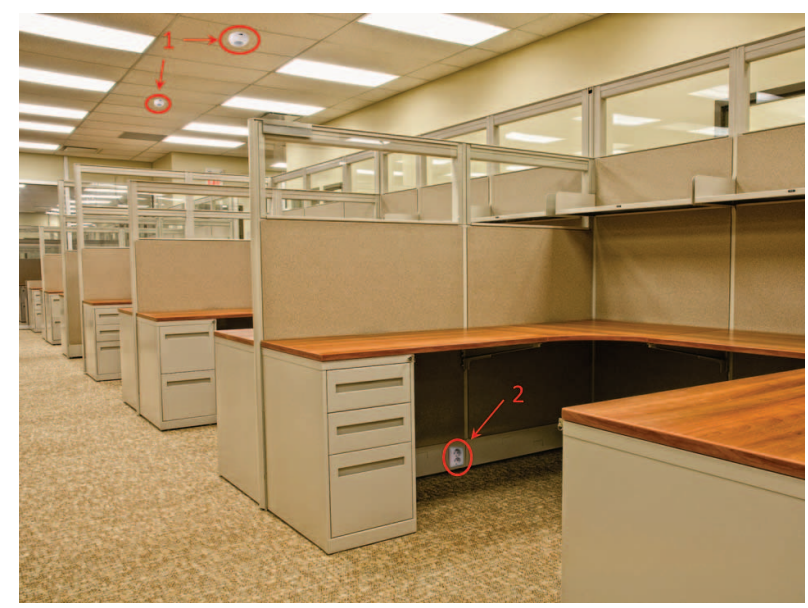

Figure 1: Illustration of sensor modalities that are frequently installed in modern buildings and considered here for activity recognition: (1) per-desk motion detectors at the ceiling for lighting and HVAC control, and (2) power meters to control plug-in appliances.

focus on a subset of sensing options that can provide information on office activities relevant for building control. Hence we neglected some data sources that may not be commonly available or are otherwise not providing information that is directly coupled to user relevant activity. In Section 6 we confirmed the relevance of the selected activity sets.

\subsection{Desk-cell and room-cell activities}

We matched general office activities, their relevance for energy-related control and information provided by the modalities described above to a shortlist of activities that can be considered by our opportunistic approach. In order to maintain scalability, we partitioned the recognition problem in desk-cell and room-cell, as there can be a variable number of desks in one room or building space.

Desk-cell activities. For an individual desk, major states include Away and Presence, where the latter can take different forms according to the actual activity: Computer work, summarizing computer-based activities, and Desk work, summarizing other desk work not actively working in front of the computer. The different activities during Presence can be used to control appliances, such as computer screens when users are not working with their computers, or to adjust lighting conditions for paper-based work. Clearly, Away and Presence as indicators of occupancy are crucial for HVAC, lighting, and appliances control.

Room-cell activities and states. Room-cell activities and states include People count, which describes the number of occupants actually working in a room. Based on People count, HVAC systems could adjust the ventilation of fresh air and temperature within a room.

All considered activities are listed together with related sensor modalities and intended use of the recognition result in Table 2. Subsequently, we derived algorithms that could process the opportunistic sensor data continuously and recognize office activities. 


\subsection{Desk activity recognition}

We chose graphical models to implement our recognition approach in desk- and room-cells. Two different methods were used: finite state machines (FSMs) and layered hidden Markov models (LHMMs). Finite state machines allowed us to describe state logic and sensor data fusion. However, FSMs are deterministic, requiring expert knowledge and manual design of states and conditions.

Unlike FSMs, HMMs are non-deterministic models, where transitions between states and observation emissions are modeled probabilistically. During the LHMM training phase, unlabeled sensor data was used. Since labeled training data was not required, LHMMs can be derived even without expert knowledge. Moreover, as we showed in our previous study [15], less than two days of training data were needed to achieve robust recognition of activities in two office rooms and LHMMs can be learned independent of a particular occupant desk. Table 1 lists all features considered in our models and Table 2 summarizes recognition goals, activity sets, features, and example applications considered in this work.

Table 1: Features derived from PIR sensors and plug-in power meters that where used in our recognition models.

\begin{tabular}{c|c|c} 
Nr. & Feature description & Symbol \\
\hline \hline 1 & PIR state & $s_{P I R}$ \\
\hline 2 & $\begin{array}{c}\text { Screen energy } \\
\text { consumption above } \\
\text { standby threshold }\end{array}$ & $v_{\text {Energy }_{i}}>\phi_{\text {Energy }}$ \\
\hline 3 & $\begin{array}{c}\text { Screen energy } \\
\text { consumption below } \\
\text { standby threshold }\end{array}$ & $v_{\text {Energy }} \leq \phi_{\text {Energy }}$ \\
\hline
\end{tabular}

Finite state machines (FSM). For per-desk PIR sensors in new building installations, the states Presence and Away are conveniently detectable by $s_{P I R_{i}}$ for desk $i$. Our Desk activity state-model however includes sub-states for Computer work and Desk work while in state Presence. The substates are recognized based on consumed energy $v_{\text {Energy }}$ of the screen at desk $i$, as shown in Figure 2. This approach assumes that the screen will enter standby mode if no user activity is detected. Consequently, if the consumed outlet energy is below a known threshold, the screen is assumed to be in standby. With this hierarchical state-model, we obtained a more specific representation of activities while working at a desk. When a user is present, but the computer has switched off the screen (hence $v_{\text {Energy }} \leq \phi_{\text {Energy }}$ ), Desk work is reported and Computer work otherwise.

Nevertheless, most PIR sensors used in office buildings are detecting motion, thus may miss to detect presence accurately. To prevent falsely reporting Away while a user is sitting motionless, we introduced an intermediate state Temporary away and prolonged Presence state for a predefined time $\Delta t_{\text {Presence. }}$. We observed that $\Delta t_{\text {Presence }}$ can be configured depending on the PIR sensor model used (see Sec. 4 for details). Only if $s_{P I R_{i}}=0$ and $v_{\text {Energy }_{i}} \leq \phi_{\text {Energy }}$, Away is reported.

Layered Hidden Markov Models (LHMMs). A hidden Markov model (HMM) is a Markov model in which the observation is a probabilistic function of hidden states. To specify an HMM, two model parameters are needed: $N$ representing the number of individual model states, and $M$,

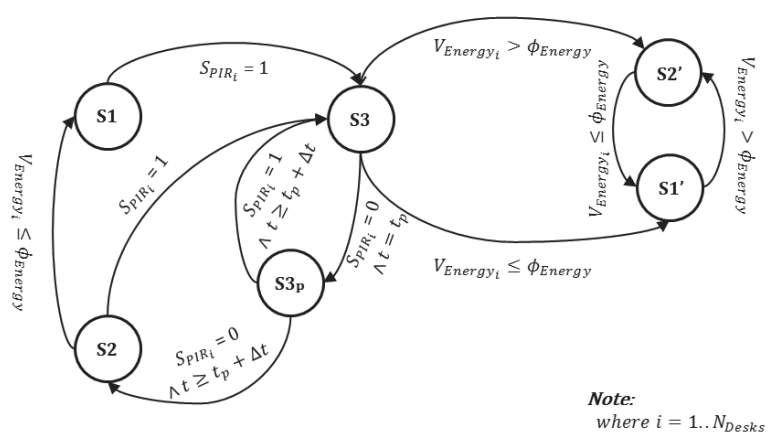

Figure 2: Desk activity state-model for classifying $S_{1}$-Away, $S_{2}$-Temporary away and $S_{3}$-Presence, $S_{1}^{\prime}$ Desk work and $S_{2}^{\prime}$-Computer work per office desk $i$. State $S_{3} p$ represents the prolonged Presence state. See Section 3 for details. The energy consumption threshold $\phi_{\text {Energy }}$ and Presence state prolongation time $\Delta t_{\text {Presence }}$ were set empirically as detailed in Section 4 .

describing the number of distinct observation symbols per state. The individual symbols are denoted as $V=\left\{v_{1}, v_{2}, \ldots\right.$ , $\left.v_{M}\right\}$. Moreover, the HMM description requires specifying three sets of probability measures $A, B$ and $\pi$, which are state-transition probability distribution, observation symbol probability distribution, and initial state distribution, respectively [21].

In order to derive HMM model parameters, unlabeled sequences of observations and states were used in a training step. The model parameter estimation, $\lambda=(A, B, \pi)$ was done using MATLAB [14].

Considering that Computer work and Desk work could exist only if the system is in a Presence state, we chose a layered HMM approach for recognizing activities. The classic LHMM approach used a bank of HMM classifiers to discriminate observation sequences [18]. The HMMs at a next level $L+1$ take outputs of the HMM at level $L$ as their inputs. In our study, the first layer consisted of three nodes to model Presence, Away and Temporary Away states, as shown in Figure 3.

Unlike the classical LHMM approach, we used the Viterbi algorithm [21] to find most probable sequences of hidden states as a result of an observed event sequence. The result of the first layer was then used as an input for the second layer, which had two nodes representing Computer work and Desk work states.

\subsection{People count estimation}

To count people in an office room, we combined information from Presence states of all desk cells $N_{\text {Desks }}$ in an office room. Our people count result is thus based on a combination of all distributed PIR sensor information. Upon a transition to or from the Presence state by our desk-cell recognition, people count was increased or decreased. To enable the system to perform rapid control decisions, we used the intermediate state Temporary away for updating the estimate, rather than Away. We applied the people count estimation based on results from both, FSM and LHMM models. 
Table 2: Summary of our opportunistic sensing approach used for recognizing office activities. Activities were selected from a general set of office activities according to their relevance for energy-related control. Desk and room cells were considered to maintain scalability for office buildings of different sizes.

\begin{tabular}{|c|c|c|c|}
\hline $\begin{array}{c}\text { Recognition } \\
\text { goal }\end{array}$ & $\begin{array}{l}\text { Opportunistic } \\
\text { sensor }\end{array}$ & Activities & $\begin{array}{l}\text { Example energy saving } \\
\text { application in offices }\end{array}$ \\
\hline \multicolumn{4}{|c|}{ Desk-cell activities per desk $i=1 \ldots N_{D e s k s}$} \\
\hline \multicolumn{4}{|c|}{$\begin{array}{r}\text { Room-cell activities and states } \\
\end{array}$} \\
\hline "People count" & Room PIR network $\left(s_{P I R_{i}} \forall i\right)$ & People count & Room conditioning \\
\hline
\end{tabular}

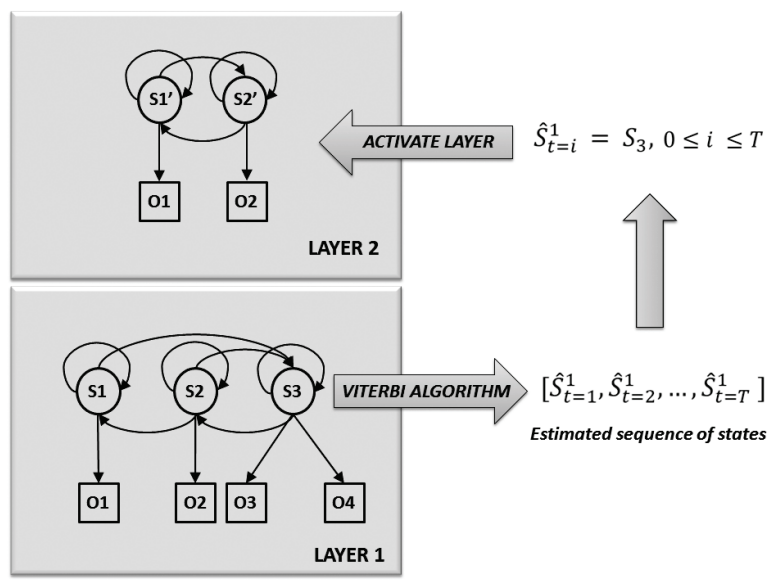

Figure 3: Layered representation of HMMs used in our recognition approach. Layer 1 consists of three states $S_{1}$-Away, $S_{2}$-Temporary away and $S_{3}$-Presence, where different PIR states and power measurements represent observations $\left(\mathrm{O}_{1}, \mathrm{O}_{2}, \mathrm{O}_{3}, \mathrm{O}_{4}\right)$. The Viterbi algorithm was used to find optimal state sequences, linked to an observed event sequence. Our estimated state sequence represented the input for the second layer, where $S_{1}^{\prime}$ - Desk work and $S_{2}^{\prime}$-Computer work states were activated during the $S_{3}$ (Presence) state.

\section{IMPLEMENTATION AND STUDY DESIGN}

This section details our living-lab implementation and study design used to analyze the opportunistic sensing approach. We describe the sensor selection to resemble commonly expectable performance. Study design considerations are described regarding opportunistic data acquisition and activity ground truth.

\subsection{Living-lab implementation}

In order to validate our approach, we set up a living-lab installation at multiple office rooms at the TU Eindhoven University campus. We investigated the scalability of our system and deployed installation in three offices with different structure: private (1-person office), a 3-persons office and a 4-persons offices. Each room cell was partitioned into several desk cells $\left(N_{\text {Desk }}\right)$ according to number of users. Figure 4 shows a schematic representation of the office layout and sensor modalities used in the installation. Table 3 shows the type and quantity of the sensors used in our installations.

Table 3: Duration of the study, desk-cells configurations and type and quantity of sensors in private, 3-persons and 4-persons offices.

\begin{tabular}{c|c|c|c} 
& $\begin{array}{c}\text { Private } \\
\text { office }\end{array}$ & $\begin{array}{c}\text { 3-persons } \\
\text { office }\end{array}$ & $\begin{array}{c}\text { 4-persons } \\
\text { office }\end{array}$ \\
\hline \hline $\begin{array}{c}\text { Days of the } \\
\text { study }\end{array}$ & $\begin{array}{c}5, \text { including } \\
2 \text { week- } \\
\text { end days }\end{array}$ & $\begin{array}{c}7 \text {, including } \\
\text { 2 week- } \\
\text { end days }\end{array}$ & $\begin{array}{c}5 \text { working } \\
\text { days }\end{array}$ \\
\hline $\begin{array}{c}\text { Number of } \\
\text { desk-cells }\end{array}$ & 1 & 3 & 4 \\
\hline \hline \multicolumn{3}{|c|}{ Office sensors } & 2 \\
\hline \hline $\begin{array}{c}\text { PIR Eltako } \\
\text { FBH63AP }\end{array}$ & 0 & 1 & 2 \\
\hline $\begin{array}{c}\text { PIR Thermokon } \\
\text { SR-MDS }\end{array}$ & 1 & 3 & 4 \\
\hline $\begin{array}{c}\text { Plug-in power } \\
\text { meters Plugwise } \\
\text { circles }\end{array}$ & 1 & 2 & 2 \\
\hline
\end{tabular}

In our living-lab installation, we used self-powered wireless PIR sensors based on the EnOcean wireless protocol ${ }^{1}$ at $868 \mathrm{MHz}$ with solar harvesting units: FBH63AP from Eltako $^{2}$ and SR-MDS from Thermokon ${ }^{3}$. All PIRs were ceiling-mounted, directly facing the desk areas. The office room height was $\sim 3.2 \mathrm{~m}$. Both models report measurements upon brightness changes of more than 10 lux, every $100 \mathrm{~s}$, and directly when motion was detected. When no motion is detected, the Eltako model waits for $100 \mathrm{~s}$ before sending an off event, while the sensor from Thermokon waits for $1000 \mathrm{~s}$. This duration was not adjustable for both models. Based on initial tests, we partly covered the PIR sensor lenses to narrow the sensor's field of view and to adjust focus to a specific desk. We set the state prolongation $\Delta t_{\text {Presence }}$ for the Eltako PIR to $240 \mathrm{~s}$, and to $0 \mathrm{~s}$ for Thermokon.

For their solar harvesting operation, EnOcean sensors required sufficient lighting conditions. Nevertheless, our mount-

\footnotetext{
${ }^{1}$ www.enocean.com

${ }^{2}$ www.eltako.com

${ }^{3}$ www.thermokon.de
} 


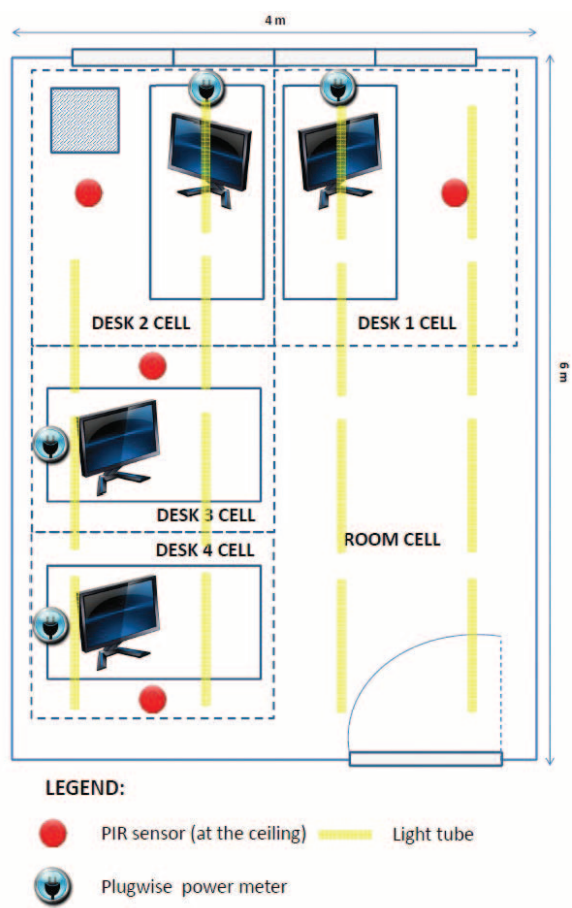

Figure 4: Schematic representation of a multi-user office room layout with four desk cells used in our investigation. Corresponding to the opportunistic sensor modalities introduced in Sec. 3, we used several sensor types and modalities. The room height is $3.2 \mathrm{~m}$.

ing locations did not hamper a continuous operation of the sensors.

To monitor energy consumption of desk screens we used Plugwise plug-in power meters ${ }^{4}$ 'Circles' that communicate via ZigBee wireless protocol at $2.4 \mathrm{GHz}$. Plugwise provided instantaneous power consumption of the screens at a sampling frequency of $\sim 1$ min. Desk screens have a maximal power consumption rating of $41 \mathrm{Wh}$ and a standby consumption of $\sim 2 \mathrm{Wh}$. We set the energy consumption threshold to $\phi_{\text {Energy }}=2.2 \mathrm{Wh}$. The energy consumption threshold was chosen in accordance with Directive 2005/32/EC [8]. Screens standby time was configured to $2 \mathrm{~min}$, based on the empirical observation in our living-lab that this setting is not considered uncomfortable for users. We used Context Recognition Network Toolbox (CRNT) [3] for recording and synchronization of the data streams via wireless USB interfaces.

\subsection{Study design}

Using the living-lab installation as detailed above, we implemented a multi-day study in the different offices with desks occupied by $\mathrm{PhD}$ students who were regular users of these desks. Participants were asked to maintain their working style as usual. No activities were scripted or prescribed in any form during the recordings. Recording durations and desk-cells configuration is shown in Table 3.

In order to obtain ground truth for the activities performed, including computer and desk work, participants were

\footnotetext{
${ }^{4}$ www.plugwise.com
}

asked to manually annotate their activities with a resolution of $1 \mathrm{~min}$ on a pencil-and-paper form. The form was designed such that regularly recurring activities could be rapidly filled in.

Since manual annotations can be inaccurate, we decided to use a pair of ultrasonic range finders (USR) as complementary sensor modalities to obtain reference data about the participants' presence. From USR data we derived presence as a threshold function of user's distance from the screen. The model SRF08 from Devantech was used and attached to the top of both sides of the screens except in the 4-persons office, where we used one sensor only. Sampling frequency was set to $1 \mathrm{~s}$. The maximum range distance was set to $1 \mathrm{~m}$ to prevent unwanted reflections from the other objects. The actual installation setup for one desk cell is shown in Figure 5.

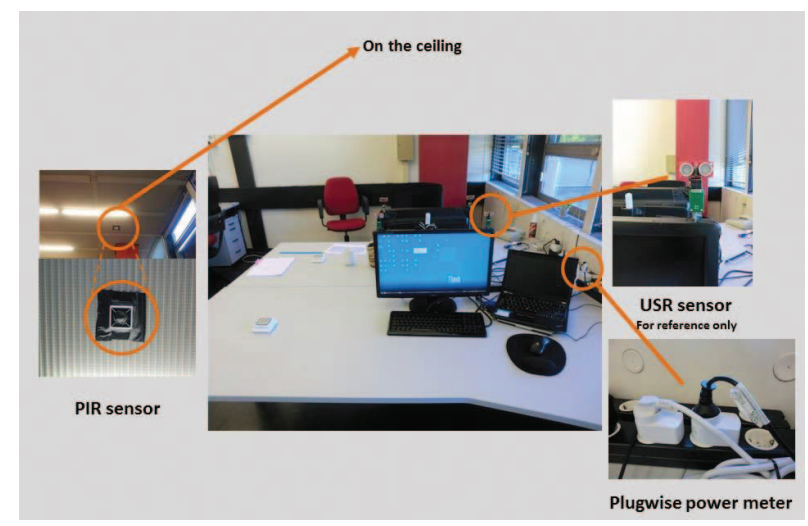

Figure 5: Living-lab installation for one desk cell, including ceiling-mounted PIR and plug-in power meter sensors. Ultrasound range sensors (USRs) were used as reference to derive ground truth for participant activities only.

\subsection{Deriving ground truth}

To complement the laborious manual annotations during the multi-day recordings, we used a USR-based activity detection of Away and Presence. In order to confirm the USRs' accuracy, we validated the classification performance in comparison to manual activity annotations of one user. The user was selected based on self-reported compliance in completing the manual annotation form.

The comparison between USR-based detection and user annotation resulted in a $94 \%$ agreement, except for the 4persons office where only one USR was available. We considered this agreement as sufficient to further use the USRbased activity detection for evaluating the opportunistic sensor and recognition algorithm performances. To further obtain activity ground truth for the activities Computer work and Desk work, we merged USR-based activity detection with manual annotations of the users. In the 4-persons office dataset, manual annotations were used as they were found to be more accurate.

Subsequently, reference for people count was derived by considering the USR-based results from all desk cells. When the USR-based detection changed from Away to Presence, reference people count was increased, when passing to Away, reference people count was decreased. 


\section{RECOGNITION ANALYSIS}

Figure 6 illustrates the sensor readings for one participant during a typical recording day in our study, including PIR sensor, screen power consumption, and the participant's activity annotation. As the waveforms illustrate, a general activity pattern is readily observable from sensor readings.
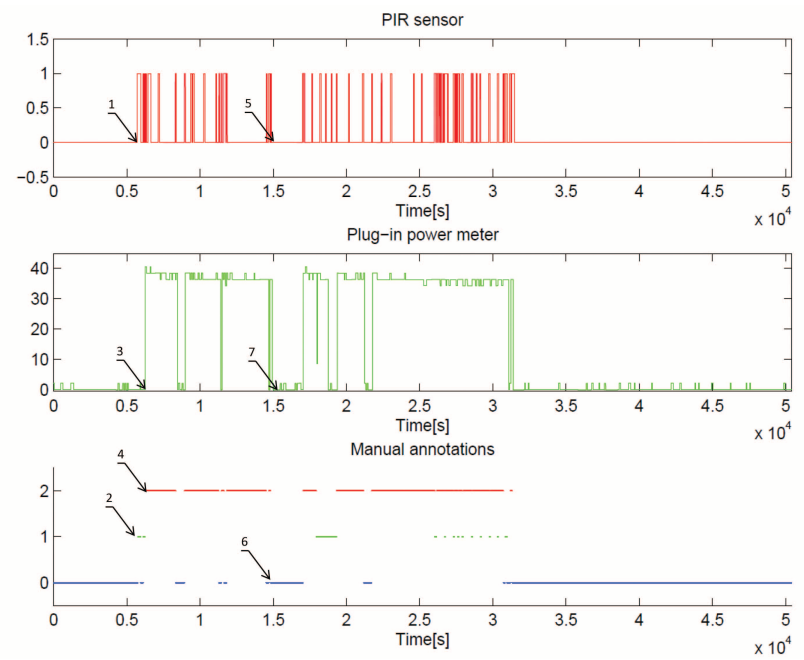

Figure 6: Example recording day from the study of one participant. Manual annotations of participant's activity were: $0=$ Away, $1=$ Desk work, $2=$ Computer work.

After entering the office room (1), the participant's initial activity was Desk work (2), which is confirmed by the screen's power consumption readings (3). Screen consumption alternated between $2 \mathrm{Wh}$ and $41 \mathrm{Wh}$ during the day according to the user's activity (4). When the participant left the desk (5), a delay was observable between the participant's activity transitions from Computer work to Away (6) and changes in the screen's consumption (7). This delay reflects the computer standby time of $2 \mathrm{~min}$. We frequently observed that the PIR sensor falsely reported Away when a user was sitting still at the desk. It can be concluded that the PIR sensor was not sufficiently sensitive to recognize low amplitude motions. Our recognition could partly compensate this effect as the screen power consumption was incorporated too.

Desk activity recognition. Activity classification results for the Desk activity recognition approach are shown in Table 4. We derived the office-specific accuracy and reported durations of classified activities to represent the data amount for each condition. As the results show, FSMs and LHMMs yielded similar performance. Overall accuracy for Presence and Away was $82.4 \%$. The results for Presence in the 3 -persons and 4-persons office were lower than those for the private office, reflecting the different characteristics of PIR sensors used. This finding confirms observations made from the waveforms above and indicates that differences in hardware characteristics can affect accuracy.

Average performance for discriminating Desk work and Computer work was $95 \%$ for both, FSMs and LHMMs. The lower accuracy for Desk work was observed for the private office only. The private office occupant reported only very few minutes of Desk work throughout the study. We at-
Table 4: Classification results of the Desk activity recognition. Since ground truth was differently derived for Presence vs. Away and Computer work vs. Desk work, separate totals are shown.

\begin{tabular}{|c|c|c|c|c|c|}
\hline \multicolumn{3}{|c|}{ Activity } & $\begin{array}{c}\text { Private } \\
\text { office }\end{array}$ & $\begin{array}{c}\text { 3- } \\
\text { persons }\end{array}$ & $\begin{array}{c}\text { 4- } \\
\text { persons }\end{array}$ \\
\hline \multirow{2}{*}{ Presence } & FSM & Accuracy $[\%]$ & 75.0 & 56.3 & 63.5 \\
\hline & LHMM & $\begin{array}{l}\text { Accuracy }[\%] \\
\text { total time }[\mathrm{h}]\end{array}$ & $\begin{array}{l}75.0 \\
11.3\end{array}$ & $\begin{array}{l}56.3 \\
60.3\end{array}$ & $\begin{array}{l}63.5 \\
93.7\end{array}$ \\
\hline \multirow{3}{*}{ Away } & FSM & Accuracy $[\%]$ & 98.0 & 96.3 & 89.5 \\
\hline & LHMM & Accuracy $[\%]$ & 98.0 & 96.3 & 89.5 \\
\hline & & total time $[\mathrm{h}]$ & 82.5 & 371.8 & 70.7 \\
\hline \multirow{3}{*}{ Total } & FSM & Accuracy $[\%]$ & 87.0 & 88.3 & 72.0 \\
\hline & LHMM & Accuracy $[\%]$ & 87.0 & 88.3 & 72.0 \\
\hline & & total time $[\mathrm{h}]$ & 93.8 & 432.1 & 164.0 \\
\hline \multirow{3}{*}{$\begin{array}{l}\text { Desk } \\
\text { work }\end{array}$} & FSM & Accuracy $[\%]$ & 39.0 & 77.0 & 72.5 \\
\hline & LHMM & Accuracy $[\%]$ & 43.0 & 77.7 & 73.0 \\
\hline & & total time $[\mathrm{h}]$ & 0.3 & 5.8 & 15.4 \\
\hline \multirow{3}{*}{$\begin{array}{l}\text { Computer } \\
\text { work }\end{array}$} & FSM & Accuracy $[\%]$ & 100.0 & 97.3 & 96.5 \\
\hline & LHMM & Accuracy $[\%]$ & 100.0 & 98.3 & 94.5 \\
\hline & & total time[h] & 10.2 & 42.7 & 78.3 \\
\hline \multirow{3}{*}{ Total } & FSM & Accuracy $[\%]$ & 97.0 & 97.3 & 92.5 \\
\hline & LHMM & Accuracy $[\%]$ & 98.0 & 98.0 & 91.8 \\
\hline & & total time $[\mathrm{h}]$ & 10.6 & 48.5 & 93.7 \\
\hline
\end{tabular}

tributed the lower recognition performance to these short desk work activity interrupts of the occupant.

Figure 7 shows the average activity recognition performances for the Desk activity recognition. As the results confirm, the LHMM-based approach can obtain similar recognition performances compared to the manually designed FSMs.

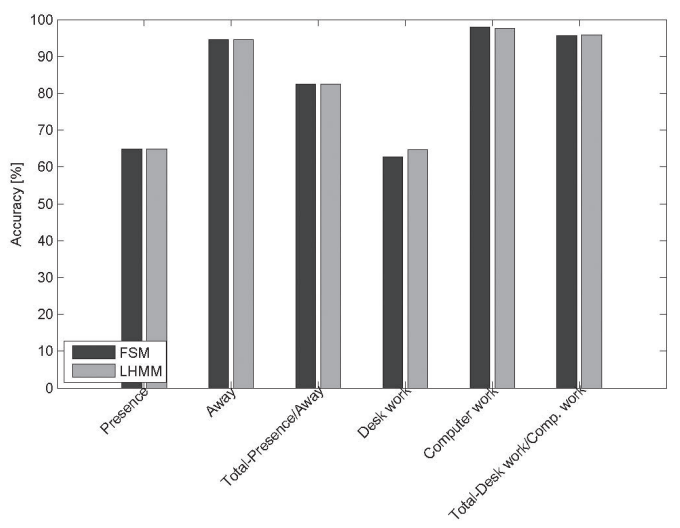

Figure 7: Average recognition performances for the Desk activity recognition. FSMs and LHMMs yielded similar results for all activities.

People count recognition. The people counting estimation performance and total people counts are shown in Table 5. Overall, an accuracy of $66.3 \%$ was obtained for FSMs and LHMMs. It could be noticed that accuracy of counting people for the 4-persons office was lower compared to the other two offices. This result can be explained by the 
low sensitivity of the PIR sensor model used in the 4-persons office, which resulted in a larger number of false negatives as discussed earlier. The accuracy per desk-cell represents the model's ability to recognize Presence and Away states, since the number of people will increase with activation of any PIR sensor and decrease with its deactivation. The relation of presence recognition and people count estimation is directly reflected in the accuracy of the private office setting.

Similar to the Desk activity recognition, FSMs and LHMMs yielded identical estimation people count estimation results. In the LHMM-based approach, we learned data model without using labeled training data, while the FSMbased approach relied on a manually state design. The results confirmed that the unsupervised learning approach applied to derive the LHMMs is viable.

Table 5: People count estimation results. FSMs and LHMMs yielded identical estimation results due to a similar presence recognition performance. The PIR sensor model deployed in the 4-persons office showed insufficient sensitivity, resulting in reduced estimation performances.

\begin{tabular}{c|c|c|c|c}
\multicolumn{2}{c|}{ Activity } & $\begin{array}{c}\text { Private } \\
\text { office }\end{array}$ & $\begin{array}{c}\text { 3- } \\
\text { persons } \\
\text { office }\end{array}$ & $\begin{array}{c}4- \\
\text { persons } \\
\text { office }\end{array}$ \\
\hline \hline FSM & Accuracy [\%] & 87 & 78 & 34 \\
\hline LHMM & Accuracy [\%] & 87 & 78 & 34 \\
\hline & Total counts & 468 & 2476 & 277 \\
\hline
\end{tabular}

\section{ENERGY CONSUMPTION ANALYSIS}

We investigated whether the activities considered in our investigation are relevant for saving energy in office buildings. In this section, we compare the benefit of activitybased controls when using office-installed sensors, to several alternative control strategies without activity inference. These alternative controls can be frequently found in current BEMS.

\subsection{Simulation approach}

We used the EnergyPlus simulation software ${ }^{5}$ for this analysis. EnergyPlus is an energy analysis and thermal load simulation tool developed by the US Department of Energy. It takes into account several parameters, including weather conditions, orientation and construction of the building, HVAC system, and occupancy. Key parameters of our simulation are shown in Table 6.

For all energy consumption simulations, we considered the 4-person multi-user office room shown in Figure 4 as an example. This room represents one thermal zone. We chose a fan coil unit as HVAC system and used yearly weather data for Amsterdam, the Netherlands, to simulate realistic environmental conditions. Space conditioning was determined according to setpoints that are typically applied in central Europe (see Tab. 6). The lighting system in this office room consisted of 15 dimmable fluorescent light tubes (length: $1200 \mathrm{~mm})$, rated at $36 \mathrm{~W}$ per tube.

\subsection{Desk activity recognition}

Here we focused on lighting as one example to assess potential energy savings of activity-based control. To compare

\footnotetext{
${ }^{5}$ apps1.eere.energy.gov/buildings/energyplus
}

Table 6: Simulation parameters used in our energy consumption analysis to assess the benefit of activity sensing to save energy.

SIMULATION PARAMETERS

\begin{tabular}{c|c}
\hline \hline HVAC system & $\begin{array}{c}\text { Fan coil unit, } \\
1 \text { zone }\end{array}$ \\
\hline Lighting system & $\begin{array}{c}15 \text { dimmable fluorescent tubes, } \\
\text { surface mounted }\end{array}$ \\
\hline Area & $24 \mathrm{~m}^{2}$ \\
\hline Location & $\begin{array}{c}\text { Amsterdam, } \\
\text { The Netherlands }\end{array}$ \\
\hline Heating setpoints & $21.1^{\circ} \mathrm{C}$ occupied, \\
$12.8^{\circ} \mathrm{C}$ unoccupied
\end{tabular}

saving options, we considered several control types and used average activity patterns and sensor data from to our study to model user behaviours as described

Manual Control. Manual Control considers the situation where users would operate a lighting system. We assume here that the first person entering to the office room will switch lights on and the last person leaving the office will switch them off. Lights provided their maximal lux level, hence energy consumption would amount to $540 \mathrm{Wh}$. This situation can be considered as an extreme, uncontrolled condition, and serves as baseline for our comparison.

Presence-based Control. This control option considers that a PIR sensors would detect presence and consequently switch lights on. If no movement is detected, the PIR will switch lights off. The lights provide maximal lux level when activated. We derived PIR activations by combining measurements of all individual PIR sensors in our study.

Presence-per-desk-based Control. In the considered office room four light tubes are dedicated to each desk, except for desk 4, where there are only three tubes (see Figure 4). When $s_{P I R_{i}}=1$ for desk $i$, lights dedicated to desk $i$ will be activated and on maximal lux level. When $s_{P I R_{i}}=0$ desk lights will be deactivated.

Activity-based Control. According to standard (BS EN 12464-1:2011), lower lighting levels ( 500 lux) are sufficient for computer work, while desk-related work requires $\geq 750$ lux. For activity-based control, we simulated a reduction of light level by $\sim 30 \%$ during Computer Work and maintained lights maximal lux level during Desk Work. In our study, at least three light tubes were dedicated to each desk, providing total maximum of $7500 \mathrm{~lm}$ per desk. Per desk area $\left(\sim 5 \mathrm{~m}^{2}\right)$, the available lux level was thus 1500 lux. If no presence was detected, lights would go off. Common lighting of the room was activated according to general room presence.

\section{Analysis results.}

In our simulations, we used actual data recorded from the 4-person office of our living-lab (see Table 3). The average power consumption per year of all control options is shown in Figure 8. For Manual Control, average power consumption on a yearly basis was $1199.48 \mathrm{kWh}$. For Presence-based Control, consumption decreased by $25.4 \%$. When presence per desk was considered (Presence-per-desk-based Control), consumption decreased by $63.2 \%$ compared to Presence-based Control. By adding information on the participant's activity and adjusting lighting level accordingly in Activity-based 
Control, average consumption per year was $257.5 \mathrm{kWh}$. Consumption in Activity-based Control was further $21.9 \%$ lower than the Presence-per-desk-based Control. Overall, the difference between Manual Control and Activity-based Control was $78.5 \%$.

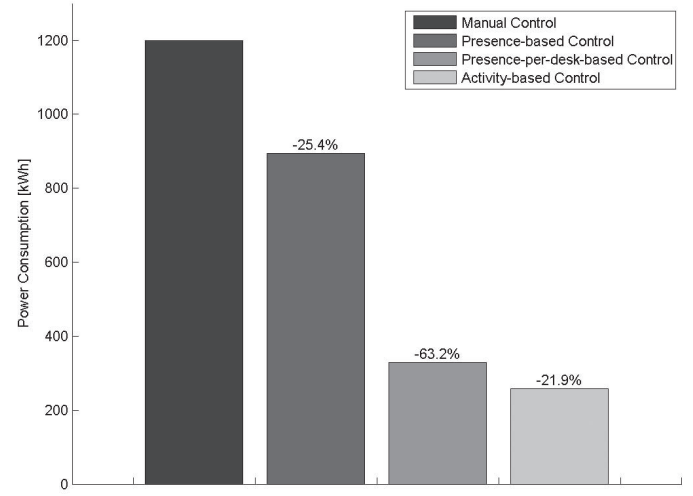

Figure 8: Lighting system average power consumption per year according to our energy consumption simulation. The results indicate savings for different control strategies, where Activity-based Control achieved an overall saving of $78.5 \%$ compared to Manual Control. This evaluation corresponds to the recognition of the 4-person office room in our livinglab.

\subsection{People count estimation}

People count in an office room has a large influence on the required ventilation rate. An increase in ventilation rate will increase power consumption of the fan coil unit. According to the ASHRAE Standard 62.1 [2] ventilation rates can be derived using:

$$
V_{b z}=R_{p} P_{z}+R_{a} A_{z},
$$

where $\mathrm{R}_{p}$ represents outdoor airflow rate per person, $\mathrm{P}_{z}$ is the population, $\mathrm{R}_{a}$ represents outdoor airflow rate per unit area and $\mathrm{A}_{z}$ is zone area.

We simulated people count in relation to required airflow, while considering a real fan coil unit. In this analysis, we used the UniTrane size $01^{6}$ from Trane, as an example device. Based on simulated airflow, a relation of people count and HVAC energy consumption is illustrated in Table 7.

We combined real data recordings and recognition from our study and energy consumption estimations to assess the effect of actual people count recognition on HVAC energy consumption. In particular, we considered the following control strategies:

Time-based Control. In many buildings without presence detection, HVAC systems are operated according to fixed schedules. Facility managers set the HVAC to active before people would usually enter a building or office room, and shut it off when people left. This control procedure did not consider actual people count in a building. For our analysis, we assumed that the HVAC system will operate at

\footnotetext{
${ }^{6}$ www.engineer.trane.com
}

maximal speed and providing maximal air flow from 6:00 to 22:00.

Manual Control. This strategy assumes that users would operate the HVAC system. We considered that HVAC system would be activated when first person enters the office and deactivated when last person leaves the office.

Presence-based Control. Here, presence as reported by any PIR sensor in our example office room would control activation of the HVAC system. The HVAC would be operated at maximal speed.

People Count-based Control. In this strategy, we consider people count estimation and would control the HVAC system's fan coil unit accordingly. Thus, based to the detect number of occupants, power consumption of a fan coil unit will change. This approach resembles simulation results illustrated above.

\section{Analysis results.}

A comparison chart of the average power consumption derived in all control strategies is shown in Figure 9. Average power consumption per year for Time-based Control and Manual Control was $104 \mathrm{kWh}$ and $55.5 \mathrm{kWh}$ respectively, which is a difference of $46.6 \%$. When using presence detection (Presence-based Control) at the office level, $25.4 \%$ was saved, compared to Manual Control. By considering the number of people in an office, fan speed was adjusted and with it air flow and power consumption. Here, energy consumption for People Count-based Control decreased by additionally $19.5 \%$, resulting in a power consumption of $33.4 \mathrm{kWh}$ on yearly basis. Nevertheless, here we estimated only the energy consumption related to fan operations, which does not consider energy needed for cooling and heating. Thus it can be expected that actual energy savings due to people count estimated could be larger.

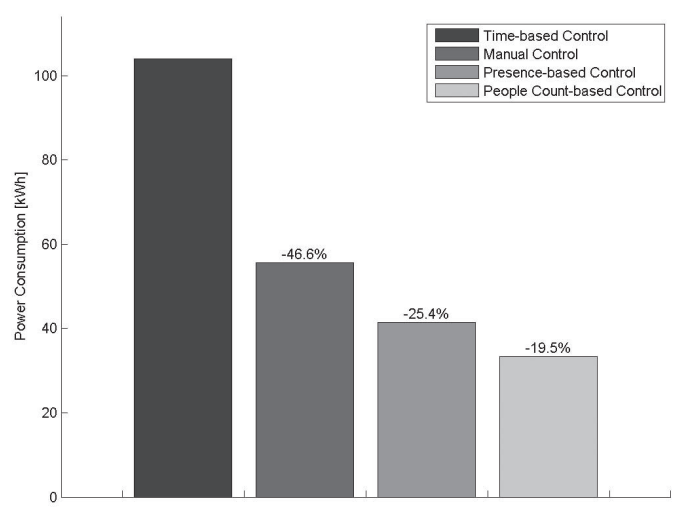

Figure 9: HVAC system average power consumption per year considering a fan coil unit operated according to different control strategies. Results show that actual people count estimates as obtained in the study can reduce energy consumption for $39.9 \%$ comparing to Manual Control.

Figure 10 illustrates the influence of different control strategies on lighting system power consumption per day: (a) Manual Control, (b) Presence-based Control, (c) Presence-perdesk-based Control and (d) Activity-based Control. In ad- 
dition, activity annotations are shown for Away, DW-Desk work, and CW-Computer work of the four occupants. Occupants were assumed to be present if they reported their involvement in computer or desk-based activity. For this illustration, power consumptions and annotations were averaged in two minute windows. As the diagrams illustrate, power consumption decreases profoundly from Manual Control to Presence-based Control, and further reductions are noticeable for Presence-per-desk-based Control. During a period from 13:00 to 14:00, most of the occupants were involved in Computer work, and lighting system consumed less than $200 \mathrm{Wh}$, for Activity-based Control. This low consumption corresponds to the decrease of $\sim 30 \%$ compared to the same period in Presence-per-desk-based control ( $\sim 300 \mathrm{Wh})$.

Table 7: Influence of people count on airflow and power consumption of a fan coil unit. We considered here the HVAC unit UniTrane size 01 from Trane.

\begin{tabular}{c|c|c} 
Number of people & Airflow $\left[\mathrm{m}^{3} / \mathbf{h}\right]$ & Power $[\mathbf{W}]$ \\
\hline \hline $\mathbf{0}$ & 0 & 0 \\
\hline $\mathbf{1}$ & 36.36 & 17 \\
\hline $\mathbf{2}$ & 72.72 & 23.84 \\
\hline $\mathbf{3}$ & 109.44 & 25 \\
\hline $\mathbf{4}$ & 145.80 & 25 \\
\hline
\end{tabular}

\section{DISCUSSION AND CONCLUSIONS}

In this work, we investigated the potential of using a subset of commonly installed office building sensors for recognizing activities that are relevant for energy saving in appliances and building systems. While these sensors are currently installed in buildings to directly control appliances, lighting, and HVAC, we used them to extract more detailed office activities. We selected desk-related activities and people count in office rooms. FSM and LHMM recognition models were implemented to capture state logic and data fusion. As we showed here, the models and approach could be applied in private and multi-user offices.

Our living-lab study helped to confirm that standard office sensors are in principle sufficient for the recognition task. We consider this result relevant, as the considered sensor modalities and similar ones are frequently found in modern or recently refurbished office buildings and require minimal maintenance. While such installed sensors are intended for closed-loop operation, sensor are often integrated into wired or wireless building networks, thus information can be intercepted. Thus, our concept could be applied without additional sensor installation, as it was frequently assumed in previous investigations.

The activity recognition accuracy of our system could be compared to the study of Nguyen et al. [16], who used dedicated infrared, pressure and acoustic sensors. The authors focused on similar activities in an experimental office room occupied by a single user and recorded for five working days. Activities corresponding to Away and Computer work could be recognized at $96.5 \%$ and $100 \%$, which is similar to the $98.0 \%$ and $100 \%$ obtained in our study, respectively. We observed lower accuracies for Presence (75.0\%) and Desk work (43.0\%), compared to $94.3 \%$ and $\sim 94.9 \%$ (Working without $P C$ ) in their study. We interpret that the reduced performances in our "Private office" setting could be explained by the small recording time for Desk work and by using a PIR sensor and a power meter alone. Beside motion sensors, pressure sensors in chairs and microphones were used in the study of Nguyen et al. When compared to the overall performance across all offices in our study, we assume that the diversity in occupation with multiple users and natural working habits in our living-lab could explain differences. Unlike our study, where users were present for $165.34 \mathrm{~h}$ and away for $525 \mathrm{~h}$, in their study only $4.42 \mathrm{~h}$ and $5.2 \mathrm{~h}$ were recorded, respectively.

Our energy consumption analysis showed energy saving potential for activity-based controls over using individual sensors only and manual control. Most of modern BMS and BEMS systems control lighting and HVAC systems based on occupancy only. Results of our study and simulations showed that by identifying user activities and people count per room, it is possible to save $21.9 \%$ and $19.5 \%$ of energy, respectively, over common BEMS systems. These results were based on our study data and recognition results in a 4-person office room. Although we consider the energy saving estimations as realistic for the considered office room, consumption may vary for other building setups that involve other users and include other installations. For example, fluorescent light tubes may not be very common in newly built commercial buildings. However, when considering modern LED lighting, e.g. the Philips Master LEDtube at $1200 \mathrm{~mm}$ length consuming $19 \mathrm{Wh}$, our activity-based control could still save $\sim 500 \mathrm{kWh}$ per year for our example office room.

In our study, we divided office room into four zones where dedicated lights were operated according to activities. If an office room provides common lights for all zones as part of the overall lighting, per-room savings obtained by activitybased control will depend on the ratio between common lights and desk-related lights. While, additional common lights would decrease the saving potential, many office rooms already constrain common lighting to safety requirements.

We observed that sensor models from different manufacturers require specific recognition model settings to achieve optimal performance. To an extreme, sensitivity of some particular sensor models may not be adequate for all recognition tasks here. Furthermore, in our approach, we assumed that office computers were adequately configured and suspending the screen if no activity occurred. This may be acceptable in many environments, however could be a limitation if users work without a separately controllable screen. EnergyStar ${ }^{7}$ states that $95 \%$ of deployed screens and $25 \%$ of office computers have power management features enabled, which supports our power metering approach.

While we recorded screen power in the study, our recognition approach does not require power metering. As alternative, a computer software could be used to track mouse and keyboard activities and thus identify computer work. More generally, office buildings include a variety of installations and appliances. We consider that our approach could be adapted to available sensor resources in a given building.

Since we modeled activities per desk-cell and used deskspecific sensors, information regarding the activity of individual occupants could be revealed. However, for our recognition approach it is not required to identify and track occupants.

Further elaboration of the recognition models and additional sensors, such as door and window switches, could in-

\footnotetext{
${ }^{7}$ www.energystar.gov
} 

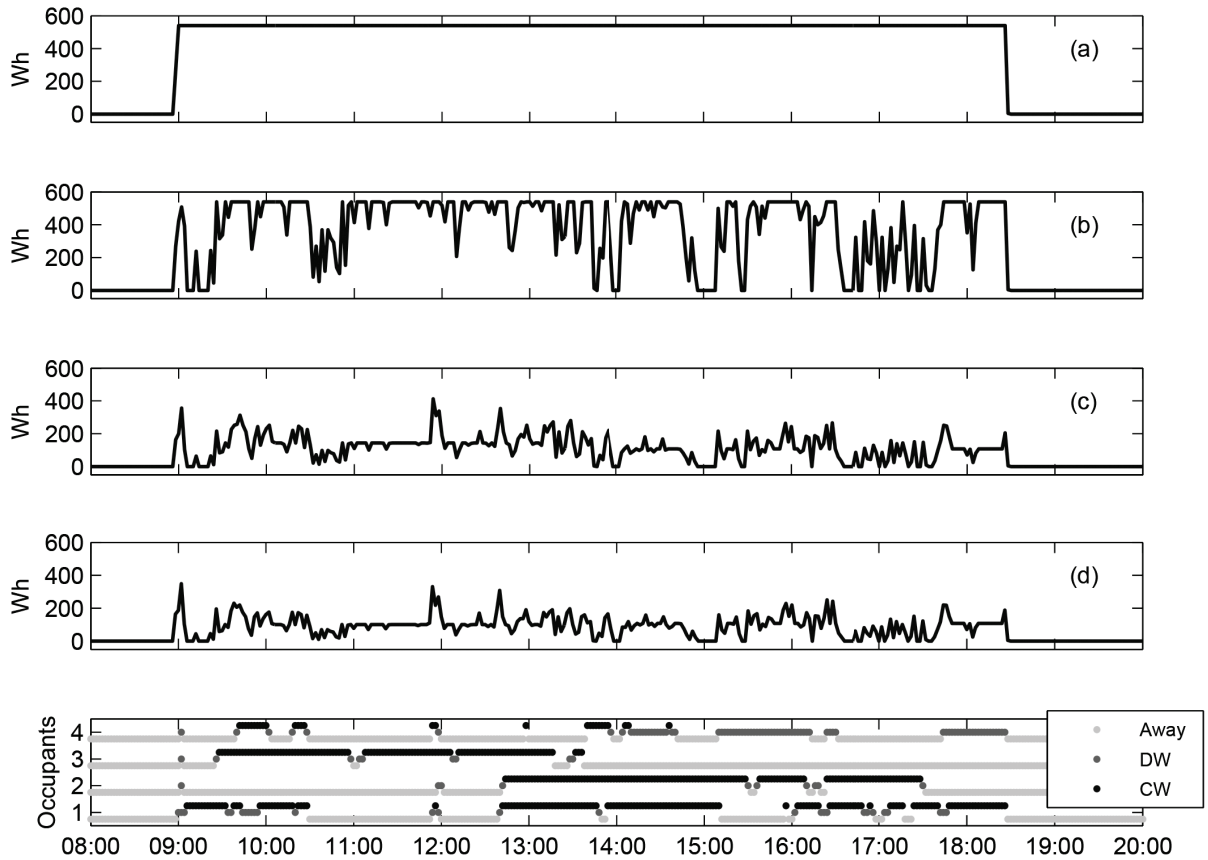

Figure 10: Illustration of the lighting system power consumption per day. The consumption traces were simulated based on the occupant activity annotations of four office users shown in the bottom plot (DW: Desk work, CW: Computer work). The following control strategies were considered: (a) Manual Control, (b) Presencebased Control, (c) Presence-per-desk-based Control, (d) Activity-based Control. Power consumptions and annotations were averaged using two minute windows.

crease the activity-based control options in buildings. The effort to configure model parameters during the deployment could be minimised through automatic teach-in procedures, similar to the commissioning of current building sensor networks.

Further studies, involving longer recording periods, more office rooms and participants should be conducted in order to confirm the recognition accuracy and potential energy savings in real office settings, as the living-lab used in this work.

\section{ACKNOWLEDGMENTS}

The work was kindly supported by the EU FP7 project GreenerBuildings, contract no. 258888, and the Netherlands Organisation for Scientific Research (NWO) project EnSO, contract no. 647.000.004.

\section{REFERENCES}

[1] Y. Agarwal, B. Balaji, R. Gupta, J. Lyles, M. Wei, and T. Weng. Occupancy-driven energy management for smart building automation. In Proceedings of the 2nd ACM Workshop on Embedded Sensing Systems for Energy-Efficiency in Building, BuildSys '10, pages 1-6, New York, NY, USA, 2010. ACM.

[2] American Society of Heating, Refrigerating and Air Conditioning Engineers, Inc. Ansi/ashrae standard 62.1-2010, ventilation for acceptable indoor air quality, 2010.

[3] D. Bannach, O. Amft, and P. Lukowicz. Rapid prototyping of activity recognition applications. IEEE Perv Comput, 7(2):22-31, April-June 2008.
[4] D. T. Delaney, G. M. P. O'Hare, and A. G. Ruzzelli. Evaluation of energy-efficiency in lighting systems using sensor networks. In Proceedings of the First ACM Workshop on Embedded Sensing Systems for Energy-Efficiency in Buildings, BuildSys '09, pages 61-66, New York, NY, USA, 2009. ACM.

[5] V. L. Erickson and A. E. Cerpa. Occupancy based demand response hvac control strategy. In Proceedings of the 2nd ACM Workshop on Embedded Sensing Systems for Energy-Efficiency in Building, BuildSys '10, pages 7-12, New York, NY, USA, 2010. ACM.

[6] V. L. Erickson, Y. Lin, A. Kamthe, B. Rohini, A. Surana, A. E. Cerpa, M. D. Sohn, and S. Narayanan. Energy efficient building environment control strategies using real-time occupancy measurements. In Proceedings of the First ACM Workshop on Embedded Sensing Systems for Energy-Efficiency in Buildings, BuildSys '09, pages 19-24, New York, NY, USA, 2009. ACM.

[7] European Commission. European union directive on the energy performance of buildings (EPBD). Technical Report 2002/91/EC, European Commission, 2002.

[8] European Commission. Guidelines accompanying commission regulation (ec) no 1275/2008, 2009. http://ec.europa.eu/energy/efficiency/ ecodesign/doc/legislation/guidelines_for_smes_ 1275_2008_okt_09.pdf.

[9] J. E. Froehlich, E. Larson, T. Campbell, C. Haggerty, J. Fogarty, and S. N. Patel. Hydrosense: infrastructure-mediated single-point sensing of 
whole-home water activity. In Proceedings of the 11th international conference on Ubiquitous computing, Ubicomp '09, pages 235-244, New York, NY, USA, 2009. ACM.

[10] S. K. Ghai, L. V. Thanayankizil, D. P. Seetharam, and D. Chakraborty. Occupancy detection in commercial buildings using opportunistic context sources. In PerCom Workshops, pages 463-466. IEEE, 2012.

[11] M. Jahn, T. Schwartz, J. Simon, and M. Jentsch. Energypulse: tracking sustainable behavior in office environments. In Proceedings of the 2nd International Conference on Energy-Efficient Computing and Networking, e-Energy '11, pages 87-96, New York, NY, USA, 2011. ACM.

[12] P. Jaramillo Garcia and O. Amft. Improving energy efficiency through activity-aware control of office appliances using proximity sensing - a real-life study. In SEnAml 2013: Proceedings of the 5th International Workshop on Smart Environments and Ambient Intelligence. IEEE, 2013. Accepted for publication.

[13] A. Marchiori and Q. Han. Distributed wireless control for building energy management? In Proceedings of the 2nd ACM Workshop on Embedded Sensing Systems for Energy-Efficiency in Building, BuildSys '10, pages 37-42, New York, NY, USA, 2010. ACM.

[14] MATLAB and Statistics Toolbox Release 2011b. version 7.13 .0 (R2011b). The MathWorks, Inc., Natick, Massachusetts, United States, 2011.

[15] M. Milenkovic and O. Amft. Recognizing energy-related activities using sensors commonly installed in office buildings. In SEIT '13: Proceedings of the 3rd International Conference on Sustainable Energy Information Technology. Procedia Computer Science, 2013. Accepted for publication.

[16] T. A. Nguyen and M. Aiello. Beyond indoor presence monitoring with simple sensors. In Proceedings of the 2nd International Conference on Pervasive and Embedded Computing and Communication Systems, 2012. To appear.
[17] A. G. Nuria Oliver, Eric Horvitz. Layered representation for human activity recognition. In Fourth IEEE International Conference on Multimodal Interfaces, pages $3-8,2002$.

[18] N. Oliver and E. Horvitz. A comparison of hmms and dynamic bayesian networks for recognizing office activities. In UM'05 Proceedings of the 10th international conference on User Modeling, pages 199-209. Springer, 2005.

[19] S. N. Patel, M. S. Reynolds, and G. D. Abowd. Detecting human movement by differential air pressure sensing in hvac system ductwork: An exploration in infrastructure mediated sensing. In Proceedings of the 6th International Conference on Pervasive Computing, Pervasive '08, pages 1-18, Berlin, Heidelberg, 2008. Springer-Verlag.

[20] S. N. Patel, T. Robertson, J. A. Kientz, M. S. Reynolds, and G. D. Abowd. At the flick of a switch: detecting and classifying unique electrical events on the residential power line. In Proceedings of the 9th international conference on Ubiquitous computing, UbiComp '07, pages 271-288, Berlin, Heidelberg, 2007. Springer-Verlag.

[21] L. Rabiner and B.-H. Juang. Fundamentals of speech recognition. Prentice-Hall, Inc., Upper Saddle River, NJ, USA, 1993.

[22] L. V. Thanayankizil, S. K. Ghai, D. Chakraborty, and D. P. Seetharam. Softgreen: Towards energy management of green office buildings with soft sensors. In COMSNETS, pages 1-6. IEEE, 2012.

[23] C. Wojek, K. Nickel, and R. Stiefelhagen. Activity recognition and room-level tracking in an office environment. In Multisensor Fusion and Integration for Intelligent Systems, 2006 IEEE International Conference on, page 25-30, 2006.

[24] C. R. Wren and E. M. Tapia. Toward scalable activity recognition for sensor networks. In $L o C A$, pages 168-185, 2006. 